\title{
Clinical significance of platelet derived growth factor-C and $-D$ in gastric cancer
}

\author{
NORIHITO OGAWA ${ }^{1}$, MIKITO INOKUCHI ${ }^{1}$, YOKO TAKAGI ${ }^{2}$, HIROFUMI SUGITA ${ }^{1}$, \\ KEIJI KATO ${ }^{1}$, KAZUYUKI KOJIMA ${ }^{3}$ and KENICHI SUGIHARA ${ }^{1}$ \\ ${ }^{1}$ Department of Surgical Oncology, Graduate School; ${ }^{2}$ Department of Translational Oncology; \\ ${ }^{3}$ Center for Minimally Invasive Surgery, Tokyo Medical and Dental University, Tokyo 113-8519, Japan
}

Received October 28, 2014; Accepted September 4, 2015

DOI: $10.3892 / 01.2015 .3758$

\begin{abstract}
Platelet-derived growth factor (PDGF)-C and PDGF-D are frequently upregulated in human cancers and play important roles in tumor progression, angiogenesis and metastasis. However, the distribution, frequency and prognostic value of PDGF-C and PDGF-D expression in gastric cancer have not been clarified. The present study evaluated the association between expression of PDGF-C and PDGF-D, clinicopathological factors and outcomes, in patients with gastric cancer. Gastric adenocarcinoma tumor samples were obtained from 204 patients who underwent curative gastrectomy between 2003 and 2007. The expression of PDGF-C and PDGF-D was analyzed by immunohistochemical staining. High expression of PDGF-C and PDGF-D was detected in 114 (56\%) and 151 (74\%) tumors, respectively. PDGF-D expression was significantly associated with tumor depth $(\mathrm{P}=0.039)$, histopathology $(\mathrm{P}<0.01)$, tumor stage $(\mathrm{P}=0.01)$ and recurrence $(\mathrm{P}<0.01)$, whereas PDGF-C expression correlated only with histopathology $(\mathrm{P}=0.05)$. High PDGF-D expression was also associated with significantly shorter relapse-free survival (RFS) time $(\mathrm{P}<0.01)$, whilst high PDGF-C expression was associated with marginally, but not significantly, shorter RFS $(\mathrm{P}=0.10)$. On multivariate analysis, high PDGF-D expression was determined to be an independent prognostic factor (hazard ratio, 3.3; 95\% confidence interval, 1.20-9.4; $\mathrm{P}=0.02$ ). These findings indicate that high PDGF-D expression is strongly associated with tumor progression, recurrence, distant metastasis and poor outcomes in patients with gastric cancer. PDGF-D may therefore be an independent prognostic factor and a novel therapeutic target.
\end{abstract}

Correspondence to: Mr. Norihito Ogawa, Department of Surgical Oncology, Graduate School, Tokyo Medical and Dental University, 1-5-45 Yushima, Bunkyo-ku, Tokyo 113-8519, Japan

E-mail: n-ogawa.srg2@tmd.ac.jp

Key words: gastric cancer, platelet-derived growth factor C, platelet-derived growth factor D, prognosis

\section{Introduction}

Gastric cancer is the fourth leading cause of cancer-related mortality worldwide. There are $\sim 989,600$ new cases and 738,000 mortalities per year, accounting for $\sim 8 \%$ of new cancer cases (1). Complete surgical resection is the only potentially curative treatment for localized gastric cancer. However, clinical outcomes of patients with advanced gastric cancer remain poor. The majority of patients with advanced gastric cancer experience recurrence or metastasis despite curative resection (2) and, even with intensive chemotherapy, the median survival time of patients with recurrent or metastatic disease is $\leq 13$ months (3).

Receptor tyrosine kinases, including human epidermal growth factor receptor (HER) and vascular endothelial growth factor, are important in cancer progression and are associated with survival in patients with gastric cancer (4-11). A number of anticancer drugs designed to inhibit signaling pathways of tyrosine kinases have been evaluated in patients with unresectable or metastatic gastric cancer (12-14); however, only trastuzumab (anti-HER2) has been demonstrated to be effective (15). Furthermore, only 23-24\% of cases of gastric cancer exhibit overexpression of HER2, the target of trastuzumab $(16,17)$. Thus, an improved understanding of the molecular pathogenesis involved in tumor progression and survival is necessary to establish more effective therapeutic targets and to improve outcomes in patients with gastric cancer.

Platelet-derived growth factors (PDGFs) are receptor tyrosine kinases that regulate diverse cellular functions, including cell proliferation, transformation, migration and embryonic development (18). PDGFs consist of four different polypeptide chains (PDGF-A,-B,-C and -D) that are assembled into disulfide-bonded dimers via homodimerization of heterodimers in order to play their functional role. So far, four homodimers (PDGF-AA, -BB, -CC and -DD) and one heterodimer (PDGF-AB) have been described (19). PDGF isoforms exert their biological functions by activating two structurally related receptor tyrosine kinases, PDGF receptors (PDGFRs) $\alpha$ and $\beta$. Upon binding of dimeric PDGF to PDGFR- $\alpha$ and $-\beta$, dimerization and activation of these receptors occurs. The receptors may combine to generate homo- or heterodimers, resulting in three possible combinations: PDGFR- $\alpha \alpha$, PDGFR- $\beta \beta$ and PDGFR- $\alpha \beta$, 
which have different affinities for the four PDGFs. Activated PDGF-C is a high affinity ligand for PDGFR- $\alpha$ homodimers, but fails to bind to and activate PDGFR- $\beta$ homodimers. By contrast, activated PDGF-D is a high affinity ligand for PDGFR- $\beta$ homodimers, but fails to bind to and activate PDGFR- $\alpha$ homodimers (20). PDGF-C and PDGF-D are also expressed in a number of types of tumor and various tumor cell lines, and are associated with tumor progression and angiogenesis $(21,22)$. PDGF-C overexpression is observed in glioblastoma, Ewing family sarcoma and lung carcinoma cell lines (22-24), whilst PDGF-D is frequently upregulated in prostate, lung, renal, ovarian, brain and pancreatic cancers $(21,22,25-29)$. Although PDGF-D overexpression has been observed in gastric cancer tissues when compared with normal tissues (30), the distribution, frequency and prognostic value of PDGF-D and PDGF-C expression in gastric cancer have not been clarified.

The purpose of the current study was to evaluate the association between the expression of PDGF-C and PDGF-D, clinicopathological factors and outcomes in patients with gastric cancer.

\section{Materials and methods}

Patients. The study group comprised 204 patients with primary gastric adenocarcinomas who underwent curative gastrectomy (R0) between January 2003 and December 2007 at the Department of Esophagogastric Surgery, Tokyo Medical and Dental University Hospital (Tokyo, Japan). Patient characterisitcs are summarized in Table I. No patient received anticancer treatment prior to surgery. Each tumor was classified according to the tumor-node-metastasis classification criteria recommended by the Union for International Cancer Control (31). All patients were evaluated for recurrent disease by diagnostic imaging, including computed tomography, ultrasonography and endoscopy, every 3-6 months. The median follow-up time was 60 months (range, 5-111 months). Recurrent disease was diagnosed in 51 patients (25\%). There were 48 mortalities (24\%) due to metastatic gastric cancer, and $11(5 \%)$ due to other diseases in the absence of recurrence. This study was approved by the Institutional Review Board of Tokyo Medical and Dental University. Written informed consent was obtained from all patients.

Immunohistochemical staining of PDGF-C and PDGF-D. Immunohistochemical staining was conducted using the Simple Stain MAX PO method with a Histofine Simple Stain MAX PO (MULTI) (Nichirei Biosciences, Inc., Tokyo, Japan). The goat polyclonal IgG antibody against human PDGF-C (\#sc-18228) was purchased from Santa Cruz Biotechnology, Inc. (Santa Cruz, CA, USA), and the rabbit polyclonal antibody against human PDGF-D (\#PAB4843) was purchased from Abnova (Taipei, Taiwan). All available hematoxylin and eosin-stained slides of the surgical specimens were reviewed. For each case, representative paraffin blocks were selected for immunohistochemical studies. The $4 \mu \mathrm{m}$-thick sections were cut from formalin-fixed, paraffin-embedded tissue blocks. Following deparaffinization and rehydration in graded concentrations of ethanol, antigen retrieval treatment was performed at $98^{\circ} \mathrm{C}$ (microwave) for $15 \mathrm{~min}$ in a
Table I. Characteristics of the studied patients $(n=204)$.

\begin{tabular}{lc}
\hline Characteristic & Value \\
\hline Age, years; median (range) & $64(21-92)$ \\
Gender, n (\%) & \\
Male & $156(76)$ \\
Female & $48(24)$ \\
Main location, $\mathrm{n}(\%)$ & \\
Upper third of stomach & $43(21)$ \\
Middle/lower third of stomach & $161(79)$ \\
WHO pathological type, $\mathrm{n}(\%)$ & \\
Differentiated & $104(51)$ \\
Undifferentiated & $100(49)$ \\
Depth of invasion, $\mathrm{n}(\%)$ & \\
T1a & $12(6)$ \\
T1b & $75(37)$ \\
T2 & $30(15)$ \\
T3 & $37(18)$ \\
T4 & $50(25)$ \\
Lymph node metastasis, $n(\%)$ & \\
Positive & $91(45)$ \\
Negative & $113(55)$ \\
TNM stage, $n(\%)$ & \\
IA & $73(36)$ \\
IB & $33(16)$ \\
IIA & $19(9)$ \\
IIB & $17(8)$ \\
IIIA & $19(9)$ \\
IIIBC & $21(10)$ \\
\end{tabular}

WHO, World Health Organization; TNM, tumor-node-metastasis.

Table II. Association between PDGF-C and PDGF-D expression, primary tumor and metastatic lymph nodes.

\begin{tabular}{lccc}
\hline & \multicolumn{2}{c}{$\begin{array}{c}\text { Metastatic } \\
\text { lymph nodes }\end{array}$} & \\
\cline { 2 - 2 } Primary tumor & Low & High & P-value \\
\hline PDGF-C & & & 0.88 \\
Low & 6 & 24 & \\
High & 11 & 48 & \\
PDGF-D & & & 0.92 \\
Low & 2 & 12 & \\
High & 10 & 65 & \\
\hline
\end{tabular}

PDGF, platelet-derived growth factor.

pH 9.0 retrieval solution (Nichirei Biosciences, Inc.) prior to treatment with 3\% hydrogen peroxide (Wako Pure Chemical Industries, Ltd., Osaka, Japan) for 15 min to quench endog- 
A
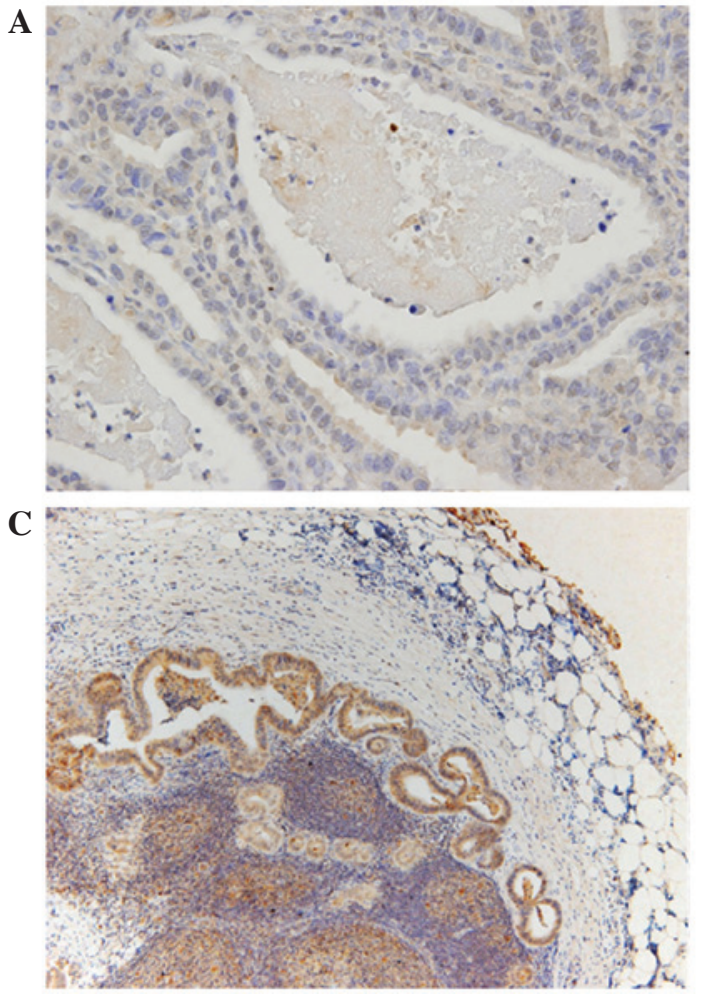

B

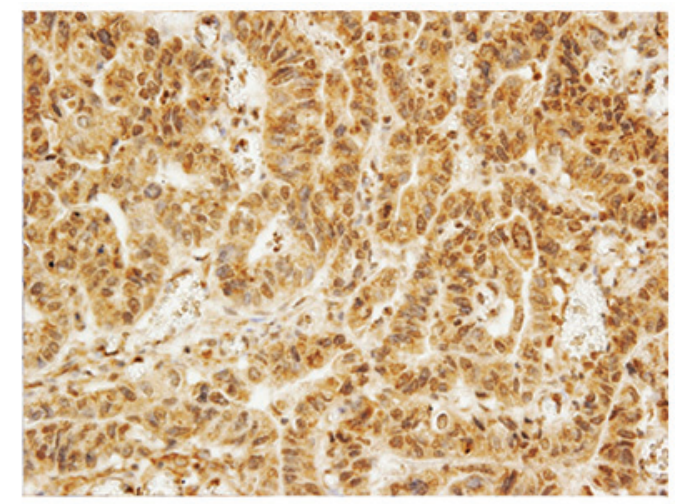

D

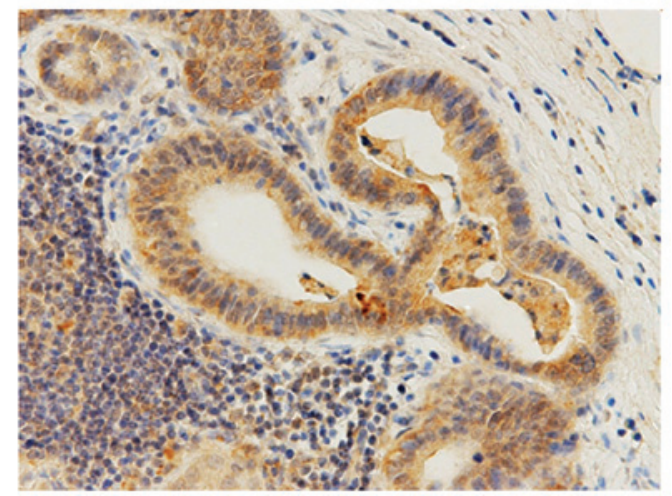

Figure 1. Representative immunostaining of gastric carcinomas for platelet-derived growth factor C: (A) none; (B) strong positive; (C and D) staining in metastatic lymph nodes (magnification, x400).

enous peroxidase activity. The slides were incubated with the primary antibodies against PDGF-C (dilution, 1:50) or PDGF-D (dilution, 1:50) overnight at $4^{\circ} \mathrm{C}$. Sections were incubated with peroxidase-labeled anti-goat or anti-rabbit antibodies [Histofine Simple Stain MAX PO (G) or (MULTI); \#414161 and \#424152; Nichirei Biosciences, Inc.] for $30 \mathrm{~min}$ at room temperature. Peroxidase activity was detected with diaminobenzidine (Histofine Simple Stain DAB solution; Nichirei Biosciences, Inc.). The slides were counterstained with $1 \%$ Mayer's hematoxylin (Wako Pure Chemical Industries, Ltd.). Expression levels of PDGF-C and PDGF-D were evaluated based on cytoplasmic staining intensity and positive frequency, and were classified into two groups (high expression or low expression). Staining intensity was scored into four grades: 0 (none), 1 (weak positive), 2 (moderate positive) or 3 (strong positive). Staining extent (positive frequency) was scored into four grades: $0,<25 \% ; 1,25 \%$ to $<50 \% ; 2,50 \%$ to $<75 \%$; or $3, \geq 75 \%$. Composite scores were derived by adding the intensity score to the extent score. For statistical analysis, composite scores of $\geq 4$ were defined as high expression, and scores of $<4$ were considered low expression. Normal tissues from the same patients were used as controls. In negative controls, the antibodies were replaced by normal goat or rabbit IgG (Santa Cruz Biotechnology, Inc.). Colorectal cancer and hepatocellular carcinoma tissues, which exhibit high expression, served as positive controls.

Statistical analysis. The $\chi^{2}$ test was used to test possible associations between the expression of PDGF-C or PDGF-D and clinicopathological factors. It was also used to assess correlations between PDGF-C and PDGF-D expressions. Kaplan-Meier curves were plotted to assess the association between PDGF-C and PDGF-D expression and relapse-free survival (RFS). Survival curves were compared using the log-rank-test. $\mathrm{P}<0.05$ was considered to indicate statistical significance. A multivariate Cox proportional hazards regression model was used to assess the prognostic significance of PDGF-C and PDGF-D expression and a number of clinicopathological factors. Statistical analysis was conducted using SPSS software, version 20 (IBM SPSS, Armonk, NY, USA).

\section{Results}

$P D G F-C$ and PDGF-D immunostaining. PDGF-C expression was predominantly located in the cytoplasm, with some in the nucleus of the tumor cells, whilst PDGF-D expression was observed only in the cytoplasm (Figs. 1 and 2). Adjacent non-malignant tissue exhibited weak or no staining of either protein. High expression of cytoplasmic PDGF-C and PDGF-D was detected in 114 (56\%) and 151 (74\%) samples, respectively. Expression of both PDGF-C and PDGF-D was observed in 98 (48\%) tumors, while 37 (18\%) tumors exhibited low expression of PDGF-C and PDGF-D. PDGF-C expression correlated with PDGF-D expression $(\mathrm{P}<0.01)$. The expression of PDGF-C and PDGF-D was also evaluated in 89 metastasis-positive lymph nodes; $81 \%$ of the samples were found to exhibit high expression of PDGF-C, and $87 \%$ displayed high expression of PDGF-D. These frequencies were higher than those observed in the primary tumors. However, there was no significant association between expression of either PDGF-C of PDGF-D in the primary tumor and that in metastatic lymph nodes (Table II). 
Table III. Clinicopathological factors and expression of PDGF-C and PDGF-D.

\begin{tabular}{|c|c|c|c|c|c|c|}
\hline \multirow[b]{2}{*}{ Variables } & \multicolumn{2}{|c|}{ PDGF-C expression, $\mathrm{n}$} & \multirow[b]{2}{*}{ P-value } & \multicolumn{2}{|c|}{ PDGF-D expression, $\mathrm{n}$} & \multirow[b]{2}{*}{ P-value } \\
\hline & Low $(\mathrm{n}=90)$ & High $(n=114)$ & & Low $(n=53)$ & High $(n=151)$ & \\
\hline Age, years & & & 0.9 & & & 0.19 \\
\hline$<70$ & 60 & 75 & & 39 & 96 & \\
\hline$\geq 70$ & 30 & 39 & & 14 & 55 & \\
\hline Gender & & & 0.59 & & & 0.02 \\
\hline Male & 70 & 85 & & 34 & 121 & \\
\hline Female & 20 & 29 & & 19 & 30 & \\
\hline Histopathology & & & 0.05 & & & $<0.01$ \\
\hline Differentiated & 37 & 63 & & 16 & 84 & \\
\hline Undifferentiated & 53 & 51 & & 37 & 67 & \\
\hline Depth of invasion & & & 0.11 & & & 0.04 \\
\hline $\mathrm{T} 1$ & 44 & 43 & & 29 & 58 & \\
\hline $\mathrm{T} 2 / \mathrm{T} 3 / \mathrm{T} 4$ & 46 & 71 & & 24 & 93 & \\
\hline Lymph node metastasis & & & 0.14 & & & 0.07 \\
\hline No & 55 & 58 & & 35 & 78 & \\
\hline N1/N2/N3 & 33 & 53 & & 18 & 73 & \\
\hline Recurrence & & & 0.07 & & & $<0.01$ \\
\hline Absent & 73 & 80 & & 49 & 104 & \\
\hline Present & 17 & 34 & & & 47 & \\
\hline TNM stage & & & 0.15 & & & 0.01 \\
\hline I & 58 & 62 & & 39 & 81 & \\
\hline II/III & 32 & 52 & & 14 & 70 & \\
\hline
\end{tabular}

PDGF, platelet-derived growth factor; TNM, tumor-node-metastasis.
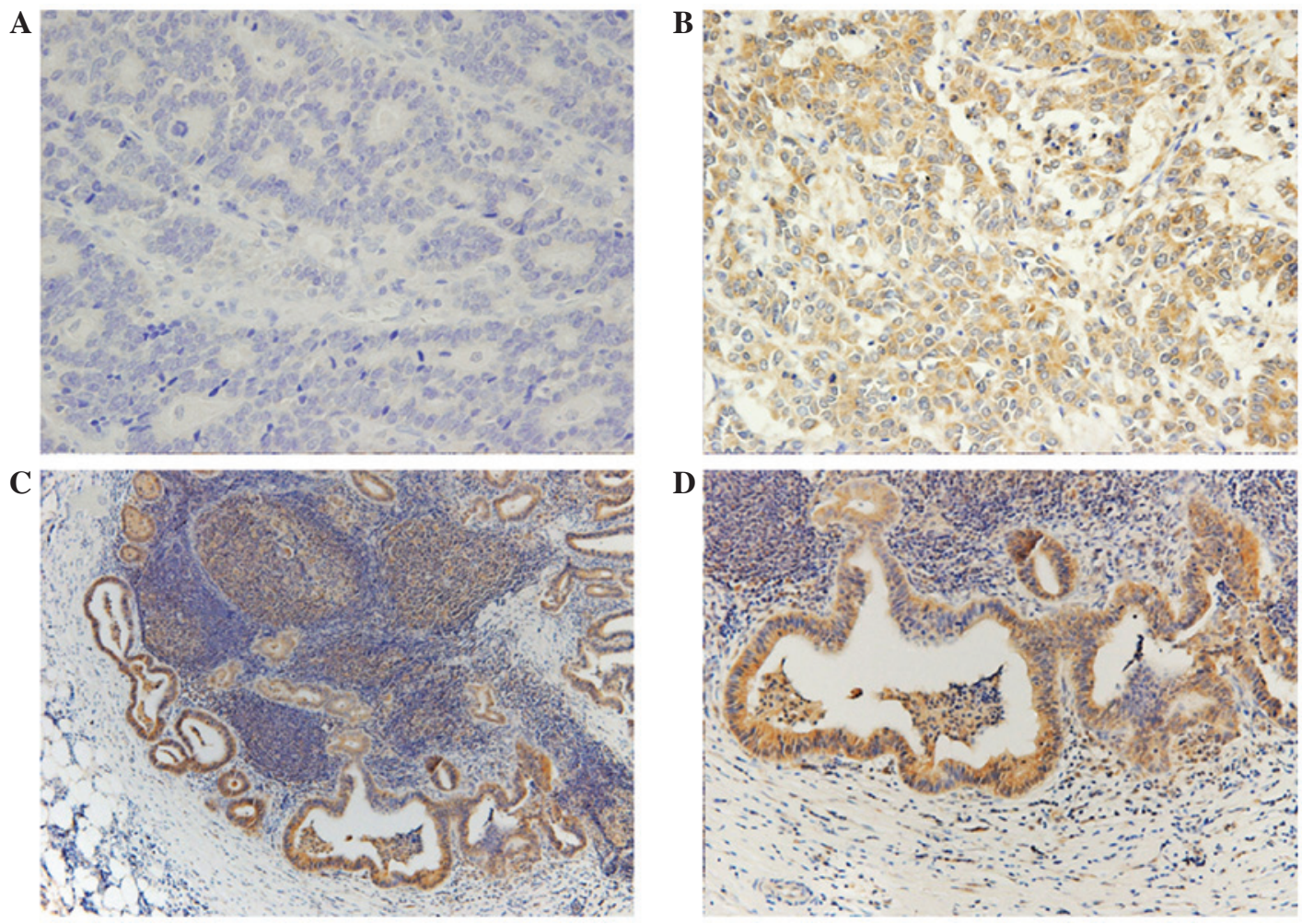

Figure 2. Representative immunostaining of gastric carcinomas for platelet-derived growth factor D: (A) none; (B) moderate positive; (C and D) staining in metastatic lymph nodes (magnification, x400). 
Table IV. Prognostic factors according to a multivariate Cox proportional hazards regression model for relapse free survival.

\begin{tabular}{|c|c|c|c|c|}
\hline Variables & Patients, $\mathrm{n}$ & $\begin{array}{c}\text { Univariate } \\
\text { analysis } \\
\text { P-value }\end{array}$ & $\begin{array}{c}\text { Hazard ratio } \\
(95 \% \text { confidence interval) }\end{array}$ & $\begin{array}{c}\text { Multivariate } \\
\text { analysis } \\
\text { P-value }\end{array}$ \\
\hline Age & & 0.70 & & \\
\hline$<70$ years & 135 & & & \\
\hline$\geq 70$ years & 69 & & & \\
\hline Gender & & 0.87 & & \\
\hline Male & 155 & & & \\
\hline Female & 49 & & & \\
\hline Histopathology & & $<0.01$ & $1.8(1.0-3.3)$ & 0.05 \\
\hline Differentiated & 100 & & & \\
\hline Undifferentiated & 104 & & & \\
\hline Tumor depth & & $<0.01$ & $9.5(2.2-41.0)$ & $<0.01$ \\
\hline $\mathrm{T} 1$ & 87 & & & \\
\hline $\mathrm{T} 2 / \mathrm{T} 3 / \mathrm{T} 4$ & 117 & & & \\
\hline Lymph node metastasis & & $<0.01$ & $5.4(2.2-13.1)$ & $<0.01$ \\
\hline NO & 113 & & & \\
\hline $\mathrm{N} 1 / \mathrm{N} 2 / \mathrm{N} 3$ & 91 & & & \\
\hline PDGF-C expression & & 0.10 & $0.8(0.4-1.5)$ & 0.48 \\
\hline Low & 90 & & & \\
\hline High & 114 & & & \\
\hline PDGF-D expression & & $<0.01$ & $3.6(1.3-10.4)$ & 0.02 \\
\hline Low & 53 & & & \\
\hline High & 151 & & & \\
\hline
\end{tabular}

PDGF, platelet-derived growth factor.
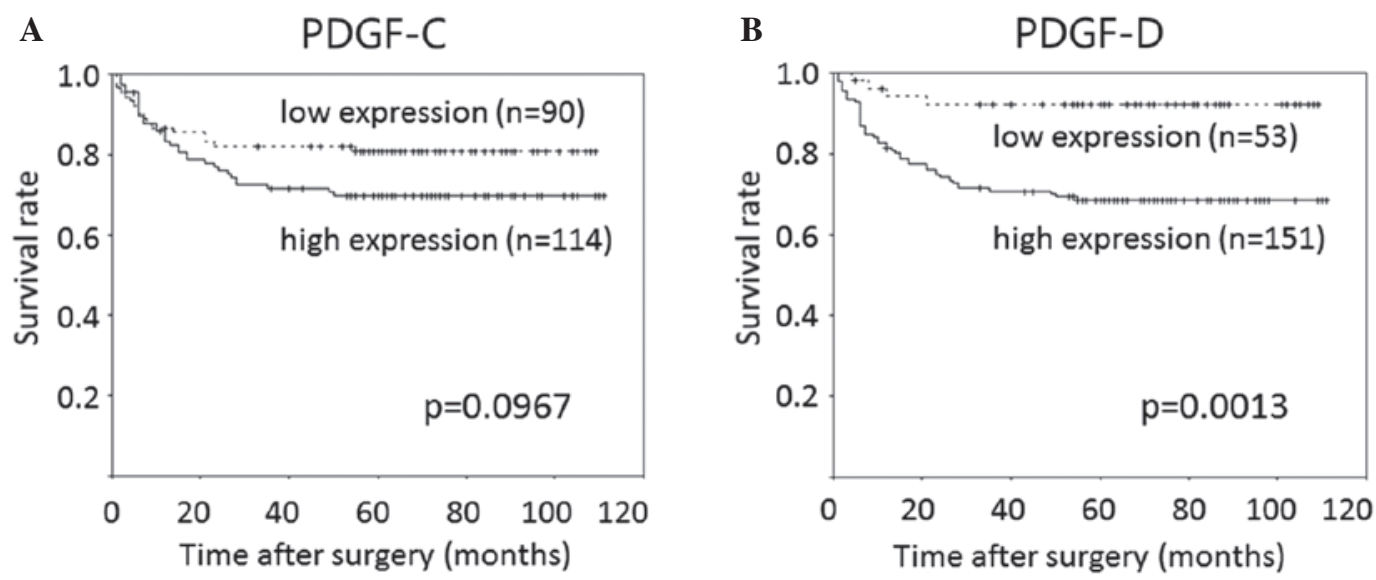

Figure 3. (A) Kaplan-Meier curves for relapse-free survival of patients with expression of PDGF-C. (B) Kaplan-Meier curves for relapse-free survival of patients with expression of PDGF-D. PDGF, platelet-derived growth factor.

Clinicopathological parameters and expression of PDGF-C and PDGF-D. High expression of PDGF-C and PDGF-D was observed more often in differentiated-type tumors than in undifferentiated-type tumors $(\mathrm{P}=0.05)$. High PDGF-C expression tended to be associated with distant metastasis and recurrence $(\mathrm{P}=0.07)$. High $\mathrm{PDGF}-\mathrm{D}$ expression significantly correlated with gender, tumor depth, tumor stage and distant metastasis and recurrence $(\mathrm{P}=0.02, \mathrm{P}=0.04, \mathrm{P}=0.01$ and
$\mathrm{P}<0.01$, respectively) and tended to be associated with lymph node metastasis $(\mathrm{P}=0.07)$ (Table III).

Prognostic significance of PDGF-C and PDGF-D expression. High PDGF-D expression was associated with significantly shorter RFS time relative to the low expression group (mean, 81 vs. 101 months; $\mathrm{P}<0.01$ ), whilst high $\mathrm{PDGF}-\mathrm{C}$ expression was associated with marginally, but not significantly, 
shorter RFS compared with the low expression group (mean, 82 vs. 90 months; $\mathrm{P}=0.10$ ). The prognostic relevance of high PDGF-C and PDGF-D expression was assessed using a multivariate proportional hazards regression model adjusted for the established clinical prognostic factors (i.e., histopathology, tumor depth, lymph node metastasis). High PDGF-D expression was determined to be an independent prognostic factor [hazard ratio (HR), 3.6; 95\% confidence interval $(\mathrm{CI}), 1.3-10.4$; $\mathrm{P}=0.02]$, whereas PDGF-C was not $(\mathrm{P}=0.48)$. Histopathology $(\mathrm{HR}$, 1.8; 95\% CI, 1.0-3.3; $\mathrm{P}=0.05)$, tumor depth (HR, 9.5; 95\% CI, 2.2-41.0; $\mathrm{P}<0.01)$ and lymph node metastasis (HR, 5.4; 95\% CI, 2.2-13.1; $\mathrm{P}<0.01)$ were also independent prognostic factors (Table IV).

\section{Discussion}

The present study demonstrated that high PDGF-D expression was significantly associated with tumor depth, recurrence, distant metastasis and poor survival in patients with gastric cancer, whereas high PDGF-C expression tended to be associated (non-significantly) with distant metastasis, recurrence and shorter RFS.

PDGF-D is frequently upregulated in various types of cancer and plays an important role in tumor progression, angiogenesis and metastasis through multiple oncogenic pathways, including the phosphatidylinositol 3-kinase/Akt, nuclear factor- $\kappa \mathrm{B}$ $(\mathrm{NF}-\kappa \mathrm{B})$, extracellular signal-regulated kinase, mammalian target of rapamycin, mitogen-activated protein kinase and Notch pathways $(12,25,26,29)$. Wang et al (26) demonstrated that PDGF-D was associated with cancer invasion and angiogenesis in pancreatic carcinomas via the regulation of Notch-1 and NF- $\mathrm{BB}$ signaling. Ustach et al (27) demonstrated that PDGF-D expression markedly accelerated tumor growth in prostate carcinoma cells, suggesting the potential oncogenic activity of PDGF-D. Xu et al (29) reported that overexpression of PDGF-D in renal cell carcinoma cells promoted tumor growth, angiogenesis and metastasis. These data suggest that PDGF-D overexpression may be associated with human cancer progression. Accordingly, the present results support the idea that high expression of PDGF-D in cancer may be important in tumor progression.

Furthermore, PDGF-D may also be associated with the epithelial-to-mesenchymal transition (EMT), an important process for tumor metastasis, via a number of signaling pathways, including Notch and NF- $\mathrm{B}$ (32-34). Kong et al (32) reported that high expression of PDGF-D was significantly associated with the induction of EMT in prostate cancer cells.

As PDGF-D exerts oncogenic activity via the regulation of tumor cell growth, invasion and metastasis, PDGF-D signaling pathways are a potential therapeutic target for the treatment of human cancers. Notably, Kong et al (25) reported that blocking the expression and activation of PDGF-D in prostate cancer cells led to the inhibition of cell proliferation, invasion and angiogenesis. In addition, Zhao et al (35) reported that silencing PDGF-D using RNA interference significantly attenuated the proliferation and invasion of gastric cancer cells that overexpressed PDGF-D. Furthermore, Lokker et al (22) demonstrated that blocking PDGF-D/PDGFR signaling inhibited survival and mitogenic pathways in glioblastoma cell lines and prevented glioma formation in a nude mouse xenograft model. However, antagonizing PDGF-D via small-molecule inhibitors or neutralizing antibodies has not been evaluated in human cancer. The current results suggest that PDGF-D may be a therapeutic target for advanced or metastatic gastric cancer. Furthermore, PDGF-D overexpression was detected in $85 \%$ of advanced gastric cancers in the present study, indicating that antagonizing PDGF-D may be a useful therapeutic strategy.

PDGF-C is also associated with tumor growth, and a number of studies have demonstrated its role in tumor growth to date $(22,36,37)$. Lokker et al (22) reported that PDGF-C autocrine signaling may play a role in the progression of brain tumors, such as glioblastoma and medulloblastoma. Anderberg et al (36) reported that that paracrine signaling of PDGF-C accelerated tumor growth through recruitment and activation of cancer-associated fibroblasts in malignant melanoma. These findings indicate that overexpression of PDGF-C accelerates tumor growth through autocrine and paracrine signaling. In fact, Yamauchi et al (37) reported that PDGF-C overexpression in colorectal cancer was associated with significantly poorer overall survival and RFS, and was an independent risk factor for recurrence. However, in the present study, PDGF-C overexpression in gastric cancer showed no significant correlation with tumor growth, distant metastasis and recurrence, in contrast to PDGF-D overexpression. This result indicates that the role of PDGF-C overexpression may be less important than that of PDGF-D in the progression of gastric cancer. However, further investigation of the molecular function of PDGF-C in gastric cancer is required.

PDGFR- $\beta$ is a receptor for PDGF-C and PDGF-D. Guo et al (38) reported that PDGFR- $\beta$ was overexpressed predominantly in tumor stromal cells and was positively correlated with tumor depth, lymph node metastasis and tumor stage in gastric cancer. Considering the results of the current study, it is possible that PDGF-D accelerates tumor growth through the activation of adjacent stromal cells; however, further studies are necessary to clarify this.

In conclusion, high PDGF-C and PDGF-D expression were associated with tumor progression and poor survival in patients with gastric cancer. In particular, PDGF-D was frequently expressed in gastric cancer and was associated with tumor progression and poor prognosis. PDGF-D signaling pathways may be a prognostic factor related to recurrence following curative surgery, and could serve as a novel target for the treatment of gastric cancer.

\section{References}

1. Jemal A, Bray F, Center MM, Ferlay J, Ward E and Forman D: Global cancer statistics. CA Cancer J Clin 61: 69-90, 2011.

2. Catalano V, Labianca R, Beretta GD, Gatta G, de Braud F and Van Cutsem E: Gastric cancer. Crit Rev Oncol Hematol 71: 127-164, 2009.

3. Koizumi W, Narahara H, Hara T, Takagane A, Akiya T, Takagi M, Miyashita K, Nishizaki T, Kobayashi O, Takiyama W, et al: S-1 plus cisplatin versus S-1 alone for first-line treatment of advanced gastric cancer (SPIRITS trial): A phase III trial. Lancet Oncol 9: 215-221, 2008.

4. Terashima M, Kitada K, Ochiai A, Ichikawa W, Kurahashi I, Sakuramoto S, Katai H, Sano T, Imamura H and Sasako M; ACTS-GC group: Impact of expression of human epidermal growth factor receptors EGFR and ERBB2 on survival in stage II/III gastric cancer. Clin Cancer Res 18: 5992-6000, 2012. 
5. Lieto E, Ferraraccio F, Orditura M, Castellano P, Mura AL, Pinto M, Zamboli A, De Vita F and Galizia G: Expresison of vascular endothelial growth factor (VEGF) and epidermal growth factor receptor (EGFR) is an independent prognostic indicator of worse outcome in gastric cancer patients. Ann Surg Oncol 15: 69-79, 2008.

6. Hayashi M, Inokuchi M, Takagi Y, Yamada H, Kojima K, Kumagai J, Kawano T and Sugihara K: High expression of HER3 is associated with a decreased survival in gastric cancer. Clin Cancer Res 14: 7843-7849, 2008.

7. Begnami MD, Fukuda E, Fregnani JH, Nonogaki S, Montagnini AL, da Costa WL Jr and Soares FA: Prognostic implications of altered human epidermal growth factor receptors (HERs) in gastric carcinomas: HER 2 and HER 3 are predictors of poor outcome. J Clin Oncol 29: 3030-3036, 2011.

8. Kim MA, Lee HS, Lee HE, Jeon YK, Yang HK and Kim WH: EGFR in gastric carcinomas: Prognostic significance of protein overexpression and high gene copy number. Histopathology 52 : 738-746, 2008

9. García I, Vizoso F, Martín A, Sanz L, Abdel-Lah O, Raigoso P and García-Muñiz JL: Clinical significance of the epidermal growth factor receptor and HER2 receptor in resectable gastric cancer. Ann Surg Oncol 10: 234-241, 2003.

10. Hirashima Y, Yamada Y, Matsubara J, Takahari D, Okita N Takashima A, Kato K, Hamaguchi T, Shirao K, Shimada Y, et al: Impact of vascular endothelial growth factor receptor 1, 2 and 3 expression on the outcome of patients with gastric cancer. Cancer Sci 100: 310-315, 2009.

11. Jüttner S, Wissmann C, Jöns T, Vieth M, Hertel J, Gretschel S, Schlag PM, Kemmner W and Höcker M: Vascular endothelial growth factor-D and its receptor VEGFR-3: Two novel independent prognostic markers in gastric adenocarcinoma. J Clin Oncol 24: 228-240, 2006.

12. Ohtsu A, Shah MA, Van Cutsem E, Rha SY, Sawaki A, Park SR, Lim HY, Yamada Y, Wu J, Langer B, et al: Bevacizumab in combination with chemotherapy as first-line therapy in advanced gastric cancer: A randomized, double-blind, placebo-controlled phase III study. J Clin Oncol 29: 3968-3976, 2011.

13. Waddell T, Chau I, Cunningham D, Gonzalez D, Okines AF, Okines C, Wotherspoon A, Saffery C, Middleton G, Wadsley J, et al: Epirubicin, oxaliplatin, and capecitabine with or without panitumumab for patients with previously untreated advanced oesophagogastric cancer (REAL3): A randomised, open-label phase 3 trial. Lancet Oncol 14: 481-489, 2013.

14. Lordick F, Kang YK, Chung HC, Salman P, Oh SC, Bodoky G, Kurteva G, Volovat C, Moiseyenko VM, Gorbunova V, et al; Arbeitsgemeinschaft Internistische Onkologie and EXPAND Investigators: Capecitabine and cisplatin with or without cetuximab for patients with previously untreated advanced gastric cancer (EXPAND): A randomised, open-label phase 3 trial. Lancet Oncol 14: 490-499, 2013.

15. Bang YJ, Van Cutsem E, Feyereislova A, Chung HC, Shen L, Sawaki A, Lordick F, Ohtsu A, Omuro Y, Satoh T, et al: Trastuzumab in combination with chemotherapy versus chemotherapy alone for treatment of HER-2 positive advanced gastric or gastro-oseophageal junction cancer (ToGA): A phase 3, open-label, randomized controlled trial. Lancet 376: 687-697, 2010.

16. Tanner M, Hollmén M, Junttila TT, Kapanen AI, Tommola S, Soini Y, Helin H, Salo J, Joensuu H, Sihvo E, et al: Amplification of HER-2 in gastric carcinoma: Association with topoisomerase IIalpha gene amplification, intestinal type, poor prognosis and sensitivity to trastuzumab. Ann Oncol 16: 273-278, 2005.

17. Yano T, Doi T, Ohtsu A, Boku N, Hashizume K, Nakanishi M and Ochiai A: Comparison of HER2 gene amplification assessed by fluorescence in situ hybridization and HER2 protein expression assessed by immunohistochemistry in gastric cancer. Oncol Rep 15: 65-71, 2006

18. Ustach CV, Taube ME, Hurst NJ Jr, Bhagat S, Bonfil RD, Cher ML, Schuger L and Kim HR: A potential oncogenic activity of platelet-derived growth factor $\mathrm{d}$ in prostate cancer progression. Cancer Res 64: 1722-1729, 2004.

19. LaRochelle WJ, Jeffers M, McDonald WF, Chillakuru RA, Giese NA, Lokker NA, Sullivan C, Boldog FL, Yang M, Vernet C, et al: PDGF-D, new protease-actovated growth factor. Nat Cell Biol 3: 517-521, 2001.

20. Andrae J, Gallini R and Betsholtz C: Role of platelet-derived growth factors in physiology and medicine. Genes Dev 22: 1276-1312, 2008.
21. LaRochelle WJ, Jeffers M, Corvalan JR, Jia XC, Feng X, Vanegas S, Vickroy JD, Yang XD, Chen F, Gazit G, et al: Platelet-derived growth factor D: Tumorigenicity in mice and dysregulated expression in human cancer. Cancer Res 62: 2468-2473, 2002.

22. Lokker NA, Sullivan CM, Hollenbach SJ, Israel MA and Giese NA: Platelet-derived growth factor (PDGF) autocrine signaling regulates survival and mitogenic pathways in glioblastoma cells: Evidence that the novel PDGF-C and PDGF-D ligands may play a role in the development of brain tumors. Cancer Res 62: 3729-3735, 2002.

23. Zwerner JP and May WA: Dominant negative PDGF-C inhibits growth of ewing family tumor cell lines. Oncogene 21: 3847-3854, 2002

24. Tejada ML, Yu L, Dong J, Jung K, Meng G, Peale FV, Frantz GD, Hall L, Liang X, Gerber HP and Ferrara N: Tumor-driven paracrine platelet-derived growth factor receptor alpha signaling is a key determinant of stromal cell recruitment in a model of human lung carcinoma. Clin Cancer Res 12: 2676-2688, 2006.

25. Kong D, Banerjee S, Huang W, Li Y, Wang Z, Kim HR and Sarkar FH: Mammalian target of rapamycin repression by 3,3'-diindolylmethane inhibits invasion and angiogenesis in platelet-derived growth factor-D-overexpressing PC3 cells. Cancer Res 68: 1927-1934, 2008

26. Wang Z, Kong D, Banerjee S, Li Y, Adsay NV, Abbruzzese J and Sarkar FH: Down-regulation of platelet-derived growth factor-D inhibits cell growth and angiogenesis through inactivation of Notch-1 and nuclear factor-kappaB signaling. Cancer Res 67: $11377-11385,2007$.

27. Ustach CV, Taube ME, Hurst NJ Jr, Bhagat S, Bonfil RD, Cher ML, Schuger L and Kim HR: A potential oncogenic activity of platelet-derived growth factor d in prostate cancer progression. Cancer Res 64: 1722-1729, 2004.

28. Ustach CV and Kim HR: Platelet-derived growth factor D is activated by urokinase plasminogen activator in prostate carcinoma cells. Mol Cell Biol 25: 6279-6288, 2005.

29. Xu L, Tong R, Cochran DM and Jain RK: Blocking platelet-derived growth factor-D/platelet-derived growth factor receptor beta signaling inhibits human renal cell carcinoma progression in an orthotopic mouse model. Cancer Res 65: 5711-5719, 2005.

30. Yang S, Shin J, Park KH, Jeung HC, Rha SY, Noh SH, Yang WI and Chung HC: Molecular basis of the differences between normal and tumor tissues of gastric cancer. Biochim Biophys Acta 1772: 1033-1040, 2007.

31. Sobin LH, Gospodarowicz MK and Wittekind C: TNM Classification of Malignant Tumours. 7th edition. Wiley-Blackwell, 2009.

32. Kong D, Wang Z, Sarkar SH, Li Y, Banerjee S, Saliganan A, Kim HR, Cher ML and Sarkar FH: Platelet-derived growth factor-D overexpression contributes to epithelial-mesenchymal transition of PC3 prostate cancer cells. Stem Cells 26: $1425-1435,2008$

33. Kong D, Li Y, Wang Z, Banerjee S, Ahmad A, Kim HR and Sarkar FH: miR-200 regulates PDGF-D-mediated epithelial-mesenchymal transition, adhesion and invasion of prostate cancer cells. Stem Cells 27: 1712-1721, 2009.

34. Wang Z, Ali S, Banerjee S, Bao B, Li Y, Azmi AS, Korc M and Sarkar FH: Activated K-Ras and INK4a/Arf deficiency promote aggressiveness of pancreatic cancer by induction of EMT consistent with cancer stem cell phenotype. J Cell Physiol 228: 556-562, 2013.

35. Zhao L, Zhang C, Liao G and Long J: RNAi-mediated inhibition of PDGF-D leads to decreased cell growth, invasion and angiogenesis in the SGC-7901 gastric cancer xenograft model. Cancer Biol Ther 9: 42-48, 2010

36. Anderberg C, Li H, Fredriksson L, Andrae J, Betsholtz C, Li X, Eriksson U and Pietras K: Paracrine signaling by platelet-derived growth factor-CC promotes tumor growth by recruitment of cancer-associated fibroblasts. Cancer Res 69: 369-378, 2009.

37. Yamauchi S, Iida S, Ishiguro M, Ishikawa T, Uetake $H$ and Sugihara K: Clinical significance of platelet-derived growth factor-C expression in colorectal cancer. J Cancer Ther 5: $11-20,2014$

38. Guo Y, Yin J, Zha L and Wang Z: Clinicopathological significance of platelet-derived growth factor B, platelet-derived growth factor receptor- $\beta$ and $E$-cadherin expression in gastric carcinoma. Contemp Oncol (Pozn) 17: 150-155, 2013. 